\title{
EFFECTS OF IPD IN NORWAY - A CASE STUDY OF THE TØNSBERG PROJECT
}

\author{
Sarah Hermine Fossum Simonsen ${ }^{1}$, Maren Holte Skoglund ${ }^{2}$, Atle Engebø ${ }^{3}$, Bjørn \\ Edmund Varegg ${ }^{4}$ and Ola Lædre ${ }^{5}$
}

\begin{abstract}
The study aims to identify the effects of implemented elements of Integrated Project Delivery (IPD) on the production phase, and the effect on team, individual and task needs. The paper advances research on IPD in practice and facilitates better transition to IPD to resolve challenges in the construction industry. The research includes a single case study of the Tønsberg Project in Norway, combined with a literature review. The case study consists of a document study and semi-structured interviews with key informants from the contractor. The research established that too many elements were attempted implemented at once, causing a tendency to fall back on traditional ways of doing things when the process lagged. Even so, the interviewees saw great potential in IPD, with more education and training. Furthermore, the experienced effects in the Tønsberg Project fulfilled team needs to a greater extent than individual and task needs. This reflects the IPD idea of the owner, contractor and designer working together as a unit and shows the value of leaders using IPD. The research is limited by a single case study and the contractor's perspective. Further work might study different projects or increase the differentiation in roles and data collection.
\end{abstract}

\section{KEYWORDS}

Integrated Project Delivery (IPD), collaboration, team model, commitment, effects.

\section{INTRODUCTION}

In traditional project delivery, projects often suffer because participant success and project success are not necessarily related. Integrated Project Delivery (IPD) is a project delivery method that integrates people, systems, organisations and practices into a single collaborative process that seeks to optimize results and value to the owner, reduce waste and maximize efficiency through all phases of the project (AIA 2007). In other words, IPD aims to make projects more successful through solving current

1 M.Sc. student, Department of Civil and Environmental Engineering, NTNU - Norwegian University of Science and Technology, Trondheim, Norway, +47 90807120, shsimons@ stud.ntnu.no

2 M.Sc. student, Department of Civil and Environmental Engineering, NTNU, Trondheim, Norway, +47 98899555, marenhs@ stud.ntnu.no

3 PhD Candidate, Department of Civil and Environmental Engineering, NTNU, Trondheim, Norway, atle.engebo@ntnu.no

4 Deputy Director and Lead Contract and Procurement, Vestfold Hospital Trust, Norway, +47 90911917, bjorn.varegg@tonsbergprosjektet.no

5 Professor, dr.ing, Department of Civil and Environmental Engineering, NTNU, Trondheim, Norway, +47 73594739, ola.ladre@ntnu.no 
construction industry problems, such as adversarial relationships and slow increases in productivity. Hospitals are particularly complex construction projects, considering size, technology and the variation in stakeholders. It is therefore natural that hospital projects experience conflicts and productivity challenges to a higher degree.

The number of research articles on IPD is generally increasing yearly (Kahvandi et al. 2017). However, there is a lack of focus on the effects of IPD in projects. In a Norwegian context, IPD is a new delivery method, and there is therefore little research on this nationally. However, IPD is becoming more relevant as interest for relational contracts increases. This paper studies the effects of implementing IPD in a Norwegian hospital project as a single case study.

Specifically, this paper seeks to identify the effects of IPD on the production phase through an analysis of the implemented contractual, technological and processual and cultural IPD elements. It therefore provides a broader perspective on IPD than earlier studies. Furthermore, the analysis provides a perspective on how IPD affects team, individual and task needs to support effective management in project organisations.

The research is limited to a single case study, as there is only one ongoing IPD project in Norway. Additionally, interviews have focused on the contractor's perspective and the production phase, but with varying roles within this stakeholder.

\section{METHOD}

This paper is based on qualitative research, including a literature review and a case study of the ongoing Tønsberg project. Firstly, the Tønsberg project is the first Norwegian project to implement the IPD delivery method. Secondly, as a large hospital project, it is worth studying the success of IPD in a complex project. The project consists of a psychiatric building and a somatic building with a total area of $44,500 \mathrm{~m}^{2}$ and cost of 335 million USD. Planned completion is March 2019 for the psychiatric building and March 2021 for the somatic building (Vestfold Hospital Trust 2016). The IPD agreement is between the owner, designers and main contractor. Additionally, three technical subcontractors participate in the shared risk and reward pool.

Following the selection of the case project, a single-case research approach was chosen. A qualitative case study approach is suitable for "how" and "why" type of research questions (Yin 2017). Thus, this approach was perceived as valid for this topic. A case study allows for researching a single phenomenon in-depth but limits the ability to generalise the results beyond the single case studied. Still, this paper documents the Norwegian construction industry's first experiences with IPD in the production phase. This case study consists of a document study and three pilot interviews.

A literature review was conducted to map and understand the various elements of IPD. Relevant literature was found through electronic searches in internationally acknowledged, peer-reviewed, multidisciplinary databases. The systematic searches in each database used identical keywords and similar filters to ensure reproducibility of the search. The bibliometric search results were followed by a qualitative evaluation of credibility, objectivity, accuracy, and relevance for each source.

The data collection was initiated by a document study. The study covered the preliminary project report and the IPD agreement for the Tønsberg project. As described by Bowen (2009), the document study provides background information and context to the case study. The document study reveals the implementation plan for the 
IPD project. However, it did not generate sufficient insight into the execution or effects of IPD. Therefore, the research was supplemented with data collected from interviews.

Interviews represent a suitable data collection method within the case study approach. Three interviewees were recruited from the contractor's part of the IPD organisation. They were chosen based both on their experience in the industry, ranging from 10 to 30 years, and their roles in the project, namely one project executive and two site engineers involved in construction and BIM. The in-depth, semi-structured interviews were conducted onsite the project in November 2018. An interview guide was developed and used during interviews to allow for preparation and to clarify any uncertainties. The interviews were audio-recorded and transcribed. The transcripts were analysed using a stepwise deductive inductive approach as described by Tjora (2012).

The literature study, document study and interviews all provide a basis for data triangulation. Triangulation strengthened the research by providing a mean for checking the data against each other (Yin 2017), and to gain satisfactory validity. The data is considered reliable, but somewhat limited due to few interviews. This effect is attempted minimised by quality control of the findings by the Tønsberg project's Deputy Director and Lead Contract and Procurement.

\section{THEORETICAL FRAMEWORK}

\section{DEFINITION AND ORIGIN OF IPD}

IPD is by the American Institute of Architects (AIA) defined as a "delivery approach that integrates people, systems, business structures and practices" (AIA 2007). IPD was created as a reaction to problems arising in traditional delivery models, and therefore aim to solve the problems to improve project feasibility. Table 1 shows Matthews and Howell's (2005) four major systematic problems with traditional contractual approaches, and how IPD solves them.

Table 1 - Problems with traditional delivery models (Matthews \& Howell, 2005)

\begin{tabular}{|c|c|c|}
\hline Problem & Result of problem & Solution using IPD \\
\hline Good ideas are held back & $\begin{array}{l}\text { Loss of time and opportunity for } \\
\text { innovation later in the process. }\end{array}$ & $\begin{array}{l}\text { Shared risk and reward } \\
\text { Increased innovation }\end{array}$ \\
\hline $\begin{array}{l}\text { Contracting limits } \\
\text { cooperation and innovation }\end{array}$ & $\begin{array}{l}\text { Minimal (if any) innovation and } \\
\text { collaboration across stakeholders. }\end{array}$ & $\begin{array}{l}\text { Multiparty contracts } \\
\text { Encourage collaboration } \\
\text { and innovation }\end{array}$ \\
\hline Inability to coordinate & $\begin{array}{l}\text { Unexpected clashes between the } \\
\text { stakeholders }\end{array}$ & Holistic coordination \\
\hline $\begin{array}{l}\text { Pressure for local } \\
\text { optimisation }\end{array}$ & $\begin{array}{l}\text { Focus on companies' own interests, } \\
\text { while neglecting the project's interests. }\end{array}$ & $\begin{array}{l}\text { Commonly defined goals } \\
\text { Global optimisation }\end{array}$ \\
\hline
\end{tabular}

The largest challenges related to IPD are market risk and fear of change. Closely following are lack of knowledge and attention to the delivery model, as well as a missing suitable legal framework (Ghassemi and Becerik-Gerber 2011).

\section{IPD ELEMENTS}

The definition of IPD by the AIA is broad, and the requirements for an IPD project must therefore be specified. Literature shows disagreement in which elements are 
required to categorise a project as IPD. Table 2 is a summary of common elements listed in various literature. In this paper, all the listed IPD elements are assumed relevant.

Table 2 - IPD elements in various literature, adapted from Aslesen et al. (2018)

\begin{tabular}{|c|c|c|c|c|c|}
\hline IPD elements & $\begin{array}{c}\text { (AIA } \\
2007)\end{array}$ & $\begin{array}{l}\text { (Kenig } \\
\text { et al. } \\
\text { 2010) }\end{array}$ & $\begin{array}{l}\text { (Ghassemi } \\
\text { and Becerik- } \\
\text { Gerber 2011) }\end{array}$ & $\begin{array}{l}\text { (Lee et } \\
\text { al. 2014) }\end{array}$ & $\begin{array}{c}\text { (Pishdad- } \\
\text { Bozorgi and } \\
\text { Beliveau 2016) }\end{array}$ \\
\hline \multicolumn{6}{|l|}{ Contract } \\
\hline Multiparty contract & & $x$ & $x$ & $x$ & $x$ \\
\hline Shared risk and reward & $x$ & $x$ & $x$ & $x$ & $x$ \\
\hline $\begin{array}{l}\text { Early involvement of key } \\
\text { participants }\end{array}$ & $x$ & $x$ & $x$ & $x$ & $x$ \\
\hline Intensified planning & $x$ & $x$ & & & $x$ \\
\hline Collaborative decision making & $x$ & $x$ & $x$ & $x$ & $x$ \\
\hline Collaborative goal definition & $x$ & $x$ & $x$ & & $x$ \\
\hline Liability waivers & & $x$ & $x$ & $x$ & $x$ \\
\hline Financial transparency & & & & $x$ & $X$ \\
\hline \multicolumn{6}{|l|}{ Technology and processes } \\
\hline Lean & & & & $x$ & $X$ \\
\hline $\mathrm{BIM}$ & & & & $x$ & $x$ \\
\hline Integrated information & $x$ & & & $x$ & $x$ \\
\hline \multicolumn{6}{|l|}{ Culture } \\
\hline Mutual respect and trust & $x$ & $x$ & & $x$ & $x$ \\
\hline Willingness to collaborate & & & & $x$ & \\
\hline Open communication & $x$ & $x$ & & $x$ & $x$ \\
\hline Co-location & & & & & $x$ \\
\hline
\end{tabular}

\section{Project TeAms in CONSTRUCTION PROJECTS}

An essential aspect of project delivery is the construction team that delivers the project. As described by Fischer et al. (2017), teams are the primary operational elements of the IPD organisation, and making the team work effectively together is therefore vital for the project outcome. However, the best structuring and management of IPD teams is not well researched.

The process of building project teams consist of a set of logical steps, such as recruiting team members, establishing a meeting structure, creating team identity and a shared sense of purpose, and designing conflict resolution mechanisms, all the while orchestrating decision-making (Larson et al. 2014). The literature on the psychology of teams and leadership agree that all teams:

- Develop their own culture and personality

- Respond to leadership

- Are motivated according to criteria usually applied to individuals

While literature explicitly states the need for teamwork in order to tackle complex projects, no universal theory on how to achieve the required level of teamwork exist. 
Adair (1986) sought to explain teamwork by linking it to leadership. His team model focuses on leadership as combining the generic needs of the task, team, and individuals, as shown in Figure 1. The task is the project purpose, and the team is the group of people put together to achieve the task (Oakland and Marosszeky 2017). Individual members within the team have their own set of needs. The team model establishes that for any group to function optimally, needs of the task, the team, and the individuals must be fulfilled. These needs are assumed to be valid for all projects.

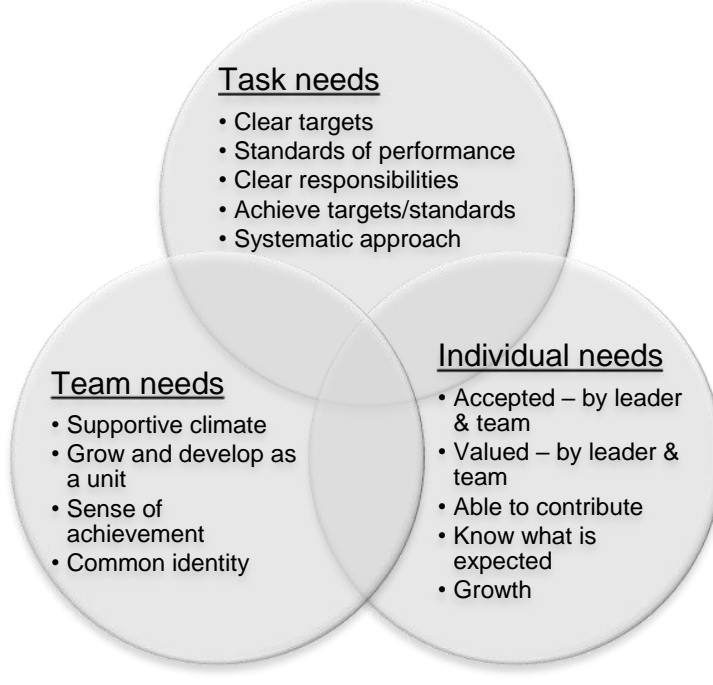

Figure 1 - Team model of leadership needs (Adair 1986)

The overlapping areas in Figure 1 illustrate the importance for leaders to combine and balance the task, team, and individual needs to achieve optimal teamwork and results. If the leader's focus is unbalanced and, for example, only fulfil the task needs, the team members might lose motivation and make less of an effort. This impairs individual needs and the overall result of the task or project (Oakland and Marosszeky 2017).

In literature on Lean construction, leadership is gaining more attention. Howell et al. (2004) stated that work management in Lean project delivery is understood as "making and keeping commitments", meaning that the nature and focus of leadership must be considered. Concerning the discussion of waste, Macomber and Howell (2004) stated that while organisations and projects manipulate material, they are better characterised by actions such as coordinating, learning, and innovating. Furthermore, these actions are tightly coupled with leadership and were not at that time discussed as a potential source for waste. Thus, leadership should be centred around producing trust through getting people to participate in a network of commitments, see each other as reliable performers, and learn to align and connect their interests with each other's interests and with those of the project (Howell et al. 2004).

Moreover, Seed (2014) proposed that the traditionally trained Project Manager is not equipped to deal with the relationship-based nature of IPD projects. Hill et al. (2007) suggested using 'Study Action Teams' to achieve the organisational transformation required for the implementation of Lean project delivery practices. In sum, the literature review provides an overview of the various elements of IPD and the vital role of the project team, set in the context of lean construction and lean project delivery. 


\section{FINDINGS AND DISCUSSION}

\section{ConTract}

The owner, contractors, and designers in the Tønsberg project jointly adapted the Hanson Bridgett's Standard Multiparty agreement to Norwegian conditions. The signed multiparty contract, the IPD agreement, formalised collaboration and use of various Lean tools and IPD elements. The interviewees did not see direct effects of the multiparty contract itself. However, the study shows that the multiparty contract is necessary to enable implementation of other IPD elements, such as early involvement of key participants. It was also used to build an IPD culture through enforcing collaboration, with collaboration tools such as workshops and BigRoom meetings. A multiparty contract should promote clear responsibilities, but this effect was not present throughout the project. Therefore, the element fulfils neither task nor individual needs. Team needs were fulfilled because the multiparty contract resulted in a common identity for the stakeholders involved.

The owner, designers, main contractor and technical subcontractors practice shared risk and reward through pooling their profits. This pool is eaten into by cost overruns but increases with cost savings. In the final settlement, it is divided up proportionally to the entry amount of each participant. The element provided a better understanding of the other stakeholders' choices and created a 'give and take' culture at the top levels of the organisation, although this effect was not present throughout the project organisation. One possible explanation is that cost and profit information do not traverse downward through the organisation. An observed issue related to the implementation of the element was that there seemed to be an imbalance between the stakeholders' share of risks and costs compared to their respective decision-making authority. Nevertheless, the element improved the feeling of a common identity between interdependent stakeholders, and therefore fulfilled the team needs. The effect of shared risk and reward did not sufficiently meet task nor individual needs.

The interviewees considered early involvement of key participants as an element with great potential and believed that it would result in a more efficient and less timeconsuming production. However, early involvement was not implemented correctly in the early stage of the project since users and the best suited people were not involved. The interviewees believed the project would benefit from early involvement in the production of the second building, because the right participants are already involved in the project and are present before the production phase starts. At this particular time, the effect from early involvement of key participants did not positively affect neither task, team nor individual needs, but it is reasonable to believe that all will be fulfilled in the second production phase.

In the Tønsberg project, intensified planning was applied to the design process, but the buffer between the design deadline and the production start was too short. The lack of buffer was a result of external circumstances that pushed the production start before the detailed design was ready. The production start imposed additional challenges on the design team, which led to frustration. The interviewees thought that lack of commitment to deadlines contributed to overdue design plans. Intensified planning fulfils all three types of needs as the element emphasises task needs such as achieving targets and standards, team needs such as growth and development as a unit, and individual needs through enabling team members to contribute and therefore feel valued. 
A decision-making body named IPD principals (IPD-P) implements the collaborative decision-making element. The IPD-P consist of one representative each from the owner, designer and main contractor. The intention was to include the entire risk and reward team in collaborative decision making. However, due to the concurrent development of the IPD agreement and preliminary project report, this was not put into practice. The interviewees stated that collaborative decision-making worked once established. However, some concern was aired regarding the members' equal voting rights, because of varying expertise on the problems at hand. Day-to-day operations in the organisation experiences some indecision, attributed to the lack of role definitions, too many workers at the same organisational level, and little commitment to tasks and deadlines. Nevertheless, collaborative decision-making contributed to a supportive climate and development of the team as a unit. The team members were able to contribute, but lack of responsibility led to missed targets. Hence, both team and individual needs were fulfilled, whereas task needs were not.

A sixth element within the contract category is collaborative goal definition. The literature review revealed consensus regarding the designer and contractor developing goals together, but discord on whether the owner should include the other stakeholders in developing overarching goals. In this project, the owner chose the goals for the entire project, without designer and contractor participation in establishing specific goals for the project. The interviewees felt little affiliation towards the goals and believed this to be a factor in the project team missing particular short and long-term aims. Lack of collaborative goals allowed the participants to act in the firms' best interest instead of the project's interests, contrary to the IPD philosophy. Therefore, in this particular project, the element did not fulfil neither task, team nor individual needs.

The shared risk and reward stakeholders signed liability waivers. The interviewees experienced more efficient problem-solving, fewer conflicts and fewer resources wasted on placing guilt. Another effect of the liability waivers was a better work environment due to the absence of blaming and 'finger pointing'. However, the study found that liability waivers could lead to a lack of commitment if wrongly implemented. An example was liability waivers being used as a shield against holding each other accountable for not delivering on time. Another explanation for this is the lack of role definition and the flat organisation structure. The liability waivers resulted in a supportive climate within the project and the growth of the team as a unit, therefore it fulfilled the needs of a team. Additionally, individual needs were fulfilled through the team members' feelings of acceptance and being valued by their peers and leaders.

Within the IPD-P and at the top levels in the project organisation there was financial transparency, which resulted in an increased understanding of costs compared to a traditional project. Regardless, further down in the project organisation there were still uncertainties about the progress of the project related to costs. Financial transparency in lower parts of the organisation aided coordination of work tasks and in avoiding misunderstandings. The financial transparency helped achieve targets and standards through a mutual understanding and acceptance of cost-based priorities and thus fulfilled task needs. Developing the team as a unit met team needs. Individual needs were not fulfilled.

\section{TECHNOLOGY AND PROCESSES}

The project implemented Lean tools such as the Last Planner System (LPS), and Target Value Delivery (TVD). The effect was regarded as positive in production, where 
weekly planning meetings and the digital program Touchplan were extensively used. The interviewees' perception of better cooperation onsite and higher efficiency in building indicate the success of this IPD element. However, LPS was discontinued in the design phase because the participants preferred traditional planning and control systems. Late deliveries suggest that successful implementation of LPS could have led to a better feeling of ownership of the various tasks and a realistic plan. However, this requires enthusiasm and commitment, which takes time to build in an organisation.

Overall, contract clauses and early planning reveal an aim to use several more Lean tools. However, most of these were new to the project team. Change resistance, time pressure and lack of training were reasons for not implementing the planned tools. However, all interviewees had a positive attitude and thought there was great potential for collaboration, economic savings and better quality through the use of Lean. In this case, Lean tools fulfilled task needs and individual needs in production, although it was not successful in design. Team needs were not met with the current implementation of Lean tools.

Building information modelling (BIM) was planned to use in 7D but is currently not used in 4D and 5D. Positive results of the BIM model are more paperless work onsite, more accessible communications in multidisciplinary meetings and ease of information onsite with BIM kiosks. However, there were also challenges such as compiling fragmented working models into one fully integrated model, and a lack of knowledge in building a BIM model. Overall, the interviewees see the positive effects of BIM in the form of multidisciplinary cooperation and communication but understand the need for more training and leadership. BIM can, therefore, be said to fulfil some task needs in the systematic approach it offers in design but did not meet team or individual needs.

Integrated information was partly successful with the implementation of common platforms, such as email domain and web hotel. Nevertheless, this process included some confusion due to consultants working on different platforms, and participants using both project-specific platforms and employers' platforms. The interviews revealed that the concept of integrated information seemed to be perceived as somewhat abstract, where interviewees focused on different aspects and had limited experiences with how integrated information affected project execution. There was evidence of awareness of the potential benefits, such as timesaving and improved collaboration, but the concept did not reach its full potential. This element, therefore, does not fulfil any needs in the team model.

\section{Culture}

Mutual trust and respect were seen as one of the most significant changes in attitude in connection with IPD. This is shown through the lack of the 'us and them' attitude in the Tønsberg project, compared to other projects where the interviewees have worked. For example, the owner showed trust in the contractor's actions and gave praise both to outside parties and within the project organisation. Both mutual trust and respect were seen as vital for project success by the interviewees. It can both be argued that trust and respect are effects of particular elements and that it is part of a circular cause and effect relationship. In the team model context, mutual trust and respect fulfil some team and several individual needs through a focus on making a supportive climate, sense of achievement and accept and value the individuals in the organisation. From that 
perspective, trust and respect are essential to ensure a balanced leadership and project success but are not directly fulfilling task needs.

Willingness to collaborate seemed to be varying across the organisation. There seemed to be some 'growing pains' in accepting an owner who is active in every project phase, and in getting used to dividing work between parties working with different billing methods. For example, team members on a fixed salary tended to finish work for people with hourly billing when the latter had surpassed the budgeted number of hours assigned to that particular task. This shows that the IPD mindset is adapted to a varying degree for different members of the project organisation. However, another effect of willingness to collaborate was a positive working environment where, typically, everyone makes the best of the situation. There was also a significant degree of willingness to collaborate within the production team, which shows that this element fulfils team needs in the team model. A more mature IPD organisation might find that willingness to collaborate can meet task and individual needs as well, although these were not fulfilled at this time in the Tønsberg project.

Open communication seemed to be present between horizontally related parties in the project organisation, for example between subcontractors. However, in early phases, there was a lack of clear role definitions and communication vertically in the organisation, resulting in indecisiveness and delays. While the interviewees saw open communication as a necessity for successful IPD, there is evidence that this takes time or needs training to develop throughout the organisation. As for this project, open communication fulfilled individual needs, through for example constructive criticism and continuous feedback. However, this element is not prevalent enough throughout the Tønsberg project to satisfy team or individual needs.

Co-location was seen as one of the most positive elements and was mentioned in several contexts. The owner, designers, and contractors were all located in a single office building on the site during the design phase and at the beginning of the production phase. However, due to cost and time concerns of the commute to the particular location, co-location has been discontinued onsite, and designers are currently in offices in the capital city. Advantages of co-location were that people got to know each other on a personal level and therefore were more inclined to give and accept constructive criticism and feedback. Additionally, communication went faster and more directly, using richer communication channels than for example emails. The project used a socalled BigRoom as a working space. However, the room design was not ideal, as many perceived it as noisy and unfit for 70 people to work in. This contributed to the limited use of co-location in the project today. In the team model, co-location gave a systematic approach in daily work with BigRoom meetings and fostered a supportive climate where the difference of opinion was welcome, as well as a common workplace for employees of different companies. Therefore, co-location fulfilled task and team needs, but not individual needs.

\section{CONCLUSIONS}

This paper aimed to identify the effects of implemented elements of IPD on the production phase, and the effect on team, individual and task needs.

It is a challenge for both individuals and organisations to implement new elements to replace established practices. In this case, not only were new elements implemented, but an entirely new delivery model, in a Norwegian context, was also put into practice. 
The findings show that, on an operational level, there exists a tendency to fall back on the traditional way of doing things when the process is lagging or obstacles occur. This explains why the effects of some elements in this particular project deviated from the theoretical framework. Executives within the different organisations understand the IPD framework, but the case study shows that this knowledge has not been appropriately conveyed throughout the organisations. The IPD framework consists of many new elements which all need time to be learned and practiced. It is a maturing process of tools and ways of working within the operative units of the organisations. If the project had not introduced so many new elements without sufficient prior training of the individuals and organisations, they might have worked better than they did.

Leadership also plays a significant part in the successful implementation of new elements, and for a project as a whole. Adair's team model indicates that if leadership is balanced between task, team and individual needs, then the likelihood of success increases (Adair 1986). Table 3 is a summary of how task, team and individual needs are fulfilled by the IPD elements in the Tønsberg project. The table is sorted by the needs fulfilled by the most elements, while the elements follow the organisation in Table 2.

Table 3 - Summary of task, team and individual needs in the Tønsberg project

\begin{tabular}{|c|c|c|c|c|c|c|c|c|c|c|c|c|c|c|c|}
\hline & \multicolumn{8}{|c|}{ Contract } & \multicolumn{3}{|c|}{$\begin{array}{l}\text { Technology } \\
\text { and processes }\end{array}$} & \multicolumn{4}{|c|}{ Culture } \\
\hline $\begin{array}{l}\text { Fulfilled } \\
\text { needs }\end{array}$ & 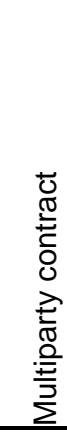 & 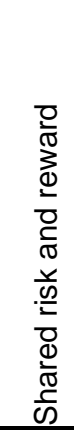 & 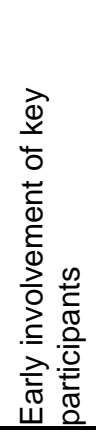 & 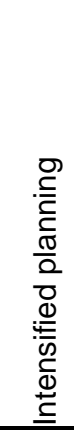 & 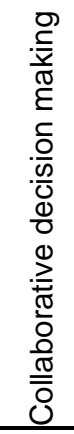 & 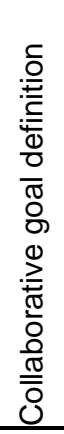 & 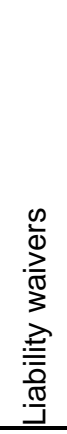 & 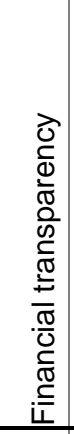 & 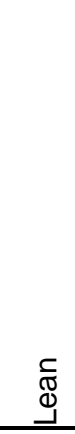 & $\sum_{\bar{m}}$ & 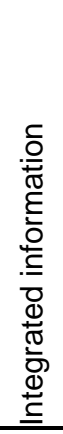 & 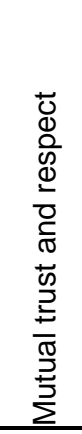 & 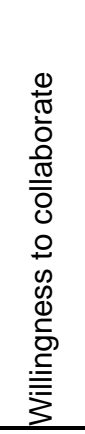 & 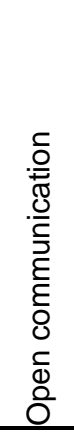 & $\begin{array}{l}\text { 음 } \\
\text { 엉 } \\
\text { o } \\
\dot{0}\end{array}$ \\
\hline Team & $x$ & $x$ & & $x$ & $x$ & & $x$ & $x$ & & & & $x$ & $x$ & & $x$ \\
\hline Individual & & & & $x$ & $x$ & & $x$ & & $x$ & & & $x$ & & $x$ & \\
\hline Task & & & & $x$ & & & & $x$ & $x$ & $x$ & & & & & $x$ \\
\hline
\end{tabular}

It is evident that team needs are fulfilled to a greater degree than task or individual needs. This reflects the IPD aim of greater collaboration between stakeholders and seeing the project team as a unit. Contrary to traditional delivery models IPD emphasises the necessity of developing a project culture to achieve a successful project. Table 3 reflects this philosophy as the elements within the culture category fulfils several needs and thereby shows that IPD supports effective leadership. The implementation of IPD in the case study is not ideal, and this is reflected in the fulfilled needs. With more successful implementation and training, one effect could be that more of the elements contribute to fulfil needs in the team model.

Further research is encouraged to increase the validity of the case study, for example through interviews with various roles representing different stakeholders. Additionally, a study after project completion can investigate quantitative data such as overall duration, cost, productivity, and quality. 


\section{REFERENCES}

Adair, J.E. (1986). Effective teambuilding. Gower, Aldershot, UK.

AIA. (2007). Integrated Project Delivery: A Guide. The American Institute of Architects. <https://www.aia.org/resources/64146-integrated-project-delivery-aguide> (27 Feb 2019).

Aslesen, A. R., Nordheim, R., Varegg, B., and Lædre, O. (2018). "IPD in Norway." In: Proc. $26^{\text {th }}$ Annual Conference of the International Group for Lean Construction (IGLC), González, V.A. (ed.), Chennai, India, 18-20 Jul 2018. pp 326-336.

Bowen, G. A. (2009). "Document Analysis as a Qualitative Research Method." Qualitative Research Journal, 9(2), pp. 27-40.

Fischer, M., Ashcraft, H. W., Reed, D., and Khanzode, A. (2017). Integrating Project Delivery. Wiley, Hoboken, New Jersey, USA.

Ghassemi, R., and Becerik-Gerber, B. (2011). "Transitioning to Integrated Project Delivery: Potential barriers and lessons learned." Lean Construction Journal, pp. 32-52.

Hill, K., Silvon, C., and Draper, J. (2007). "Another Approach to Transforming Project Delivery: Creating a Shared Mind." In: Proc. 15 th Annual Conference of the International Group for Lean Construction (IGLC), Pasquire, C.L. and Tzortzopoulos, P. (ed.), East Lansing, Michigan, USA, 18-20 Jul 2007. pp. 417-422.

Howell, G. A., Macomber, H., Koskela, L., and Draper, J. (2004). "Leadership and Project Management: Time for a Shift from Fayol to Flores." In: Proc. $12^{\text {th }}$ Annual Conference of the International Group for Lean Construction (IGLC), Bertelsen, S. and Forsmo, C.T. (ed.), Helsingør, Denmark, 3-5 Aug 2004.

Kahvandi, Z., Saghatforoush, E., Alinezhad, M., and Noghli, F. (2017). "Integrated Project Delivery (IPD) Research Trends." Journal of Engineering, Project, and Production Management, 7(2), pp. 99-114.

Kenig, M., Allison, M., Black, B., Burdi, L., Colella, C., Davis, H., Elsperman, D., Frey, J., Katherman, R., Lambert, M., Lynch, J., Maibach, D., and McKimmey, M. (2010). Integrated Project Delivery For Public and Private Owners. NASFA, COAA, APPA, AGC of America and AIA. <https://www.agc.org/integrated-projectdelivery> (27 Feb 2019).

Larson, E.W., Honig, B., Gray, C.F., Dantin, U., and Baccarini, D. (2014). Project management: The Managerial Process. McGraw-Hill education, North Ryde, New South Wales, Australia.

Lee, H.W., Anderson, S.M., Kim, Y.W., and Ballard, G. (2014). "Advancing Impact of Education, Training, and Professional Experience on Integrated Project Delivery." Practice Periodical on Structural Design and Construction, 19(1), pp. 8-14.

Macomber, H., and Howell, G. (2004). "The Two Great Wastes in Organizations." In: Proc. 12 $2^{\text {th }}$ Annual Conference of the International Group for Lean Construction (IGLC), Bertelsen, S. and Forsmo, C.T. (ed.), Helsingør, Denmark, 3-5 Aug 2004.

Matthews, O., and Howell, G. (2005). "Integrated Project Delivery An Example of Relational Contracting." Lean Construction Journal, 2(1), pp. 46-61.

Oakland, J., and Marosszeky, M. (2017). Total Construction Management: Lean Quality in Construction Project Delivery. Routledge, Abington, UK.

Pishdad-Bozorgi, P., and Beliveau, Y. J. (2016). "Symbiotic Relationships between Integrated Project Delivery (IPD) and Trust." International Journal of Construction Education and Research, 12(3), pp. 179-192. 
Seed, W. R. (2014). “Integrated Project Delivery Requires a New Project Manager.” In: Proc. 22 ${ }^{\text {nd }}$ Annual Conference of the International Group for Lean Construction (IGLC), Kalsaas, B.T, Koskela, L. and Saurin, T.A. (ed.), Oslo, Norway, 25-27 Jun 2014. pp. 3-14.

Tjora, A. (2012). Kvalitative forskningsmetoder i praksis. Gyldendal, Oslo, Norway.

Vestfold Hospital Trust. (2016). Tønsbergprosjektet Forprosjektrapport. Tønsberg: Tønsbergprosjektet. <http://tonsbergprosjektet.no> (20 Feb 2019).

Yin, R. K. (2017). Case Study Research and Applications: Design and Methods. SAGE Publications, Los Angeles, California, USA. 